\title{
DEPRESSION SYMPTOMS IN BRAZILIAN FIBROMYALGIA SYNDROME PATIENTS PARTICIPATING IN THE FACEBOOK PAGE “FIBROMYALGIA PATIENT SUPPORT GROUP”
}

Mateus Dias Antunes ${ }^{1, *}$, Cleber Vernillo de Toledo ${ }^{2}$, Amélia Pasqual Marques $^{1}$, Leonardo Pestillo de Oliveira²

1. Universidade de São Paulo, São Paulo (SP), Brazil. 2. Universidade Cesumar, Maringá (PR), Brazil.

*Corresponding author: mateusantunes@usp.br

\section{BACKGROUND}

Fibromyalgia is a syndrome that presents a complex multifactorial etiopathogenesis, not totally known, characterized by scattered musculoskeletal pains and, frequently, associated with fatigue, changes in sleep, somatic and cognitive symptoms and psychological disorders. The prevalence of fibromyalgia in the general population is from 0.2 to $6.6 \%$. The aim of this study was to investigate the symptoms of depression in patients with fibromyalgia syndrome Brazilian participants of the Facebook page "Support Group for Fibromyalgia Patients".

\section{MATERIAL AND METHODS}

It is a cross-sectional study, involving individuals diagnosed with fibromyalgia who answered an electronic form published on the Facebook page "Support Group for Fibromyalgia Patients". To assess subjects' symptoms of depression, the Beck Depression Inventory (DBI-II) was applied, a psychological test used to assess depressive symptoms, created by Aaron Beck, with Brazilian validation. For data analysis, descriptive statistics were performed.

\section{RESULTS}

The study sample consisted of 132 subjects diagnosed with fibromyalgia. Regarding the depressive traits of the studied population through the application of the DBI-II, a self-assessment instrument, it was found that $4.55 \%$ of the sample did not present depressive traits, $8.33 \%$ had a slight depression, $18.94 \%$ of the subjects already have moderate depression, while $68.18 \%$ of patients with fibromyalgia have severe symptoms of depression.

\section{CONCLUSION}

There is a high prevalence of depressive symptoms in Brazilian patients with fibromyalgia participants on the Facebook page "Support Group for Fibromyalgia Patients". The depressive symptoms of fibromyalgia affect the quality of life of people affected by this syndrome. In this sense, it is necessary to develop and apply interdisciplinary educational strategies that promote the health of individuals with fibromyal gia in Brazil. It is important for professionals involved in the diagnosis and treatment of fibromyalgia symptoms to highlight the need for psychological and psychiatric monitoring in cases of patients who have manifested or are likely to develop such disorders, and still refer these to trained professionals for treatment and prevention of disorders are effective. It is necessary for those with fibromyalgia to have representation and fight for their rights in relation to state and federal assistance programs, in order that, even to a lesser extent, symptoms are alleviated, and their rights and social benefits are guaranteed.

\section{ACKNOWLEDEGMENTS}

To the Instituto Cesumar de Ciência, Tecnologia e Inovação (ICETI). 